\title{
Unusual variability of the superficial venous system of the upper limb and its consequences for deep venous system
}

\author{
Z.M. Ziętek1, 2 (D) \\ ${ }^{1}$ Department of General Surgery and Transplantology, Pomeranian Medical University, Szczecin, Poland \\ ${ }^{2}$ Department of Normal and Clinical Anatomy, Pomeranian Medical University, Szczecin, Poland
}

[Received: 24 September 2020; Accepted: 25 November 2020; Early publication date: 23 December 2020]

\begin{abstract}
In our report we would like to present a variation of the two main superficial veins of the upper limb. In 21 (88\%) explored upper limbs, the venous system showed a pattern similar to that presented in the anatomical textbook. However, in $4(12 \%)$ others venous patterns differed from those already described. Especially in one of them the variant of the veins of the upper limb distinctly contrasted with the others. In that case, the basilic and cephalic vein, instead of the normal course to the arm where they should bypass the elbow pit, unexpectedly merged into one and formed one of the two brachial veins. Towards the axillary cavity it ran laterally over the entire arm regardless of the second brachial vein. In the armpit cavity, instead of connecting with the second one, it gave rise to an independent second vein - the accessory axillary vein. This uniqueness was based on that, independently from deep venous system, the superficial one formed their own net. The accessory axillary vein and the second brachial vein were completely formed by two main superficial veins: the basilic and cephalic vein. By describing this case we wanted to emphasize that in any surgical procedure on the upper limbs, especially on the venous system, there is a certain probability of encountering this anatomical variation. Another conclusion is that the catalogue of patterns of the venous system of the upper limb seems to be endless. (Folia Morphol 2022; 81, 1: 254-257)
\end{abstract}

Key words: venous system, upper limb, anatomical variation, surgery

\section{INTRODUCTION}

The nature of the human body inspires from the dawn of mankind to the present day. Despite new alternative methods, the anatomical dissection still remains the golden standard in the study of the anatomy of the human body [7]. Searching of new patterns or variations of structures of the human body is the most important challenge for every anatomist [10, 12]. Former postulates of clinicians addressed to anatomists, encouraging them to continue exploration of human body, have not lost their relevance $[6,8,12]$.

Variations in the venous pattern of the upper limb are very common. Conventional textbooks describe the anatomy of the venous system of the upper limb as two layouts [11]. The first one is called superficial or superfascial and the second one - deep or subfascial. These are not independent systems, but the existing anastomoses between them provide blood 


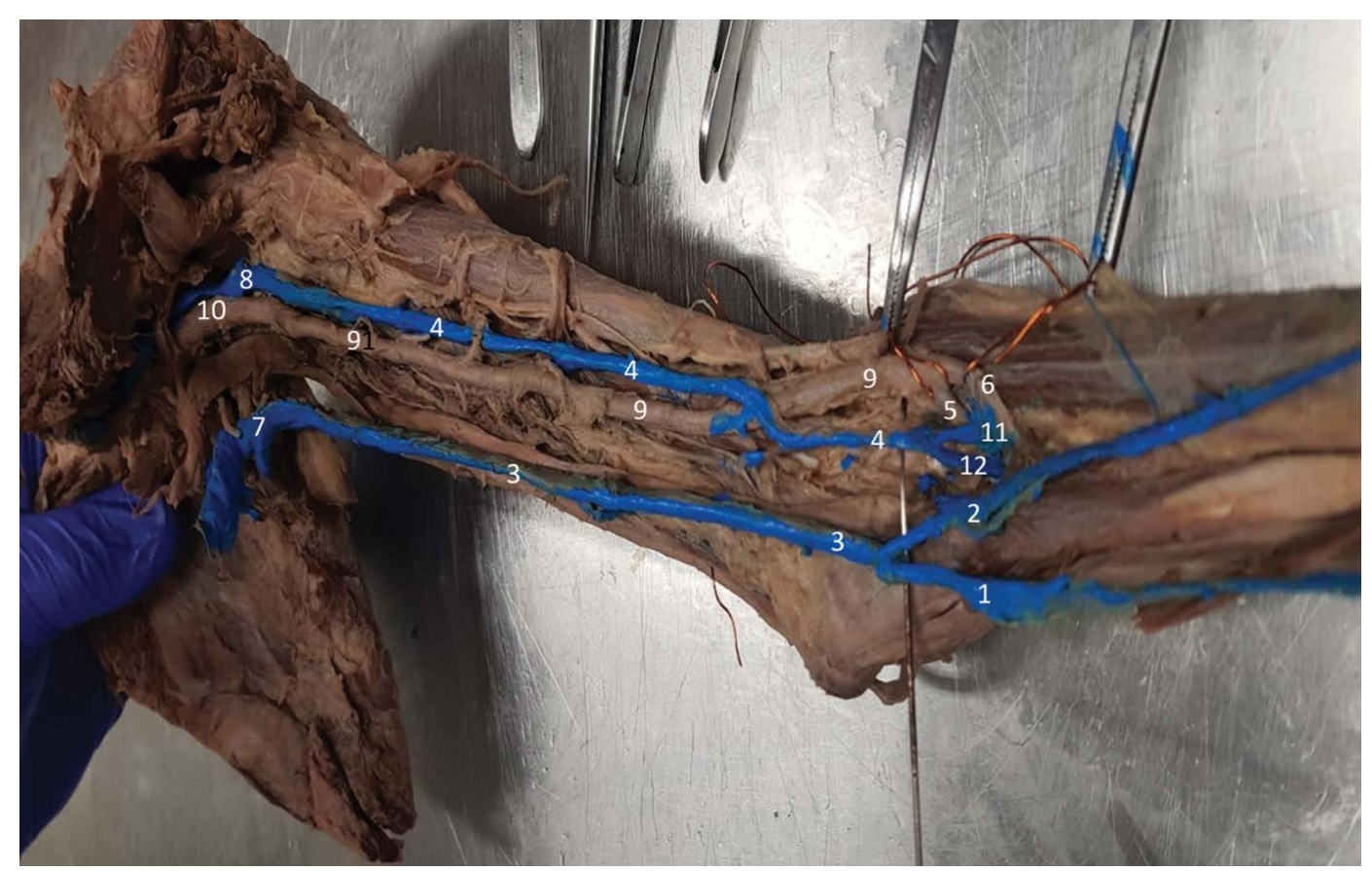

Figure 1. The unique pattern of veins of the left upper limb — the veins are blue; 1 - basilic vein; 2 - cephalic vein; 3 - "superficial" brachial vein — pulled up by probe; 4 — "deep" brachial vein — pulled up by probe; 5 — radial artery — pulled up by a garter; 6 - ulnar artery — pulled up by a garter; 7 — "superficial" axillary vein; 8 — "deep" axillary vein; 9 — brachial artery — pulled up; 10 — axillary artery; 11 - singular radial vein; 12 - singular ulnar vein; for the clarity of photography — the nervous system was missed.

flow from the superficial to the deep system, which ultimately delivers blood to the heart. The superficial system is represented by two main veins: the basilic vein and cephalic vein. At the level of the forearm and arm both these veins run along the inner and lateral side of the upper limb. Finally, in the middle of the arm, the basilic vein connects to one of the brachial veins and the cephalic vein joins the axillary vein in the deltopectoral triangle. The deep system consists of veins accompanying the arteries, whose names come from the accompanying arteries. Usually, in this system, there are two veins which run along one artery, except of the axillary and subclavian vein $[7,9]$. The number of anatomical variants of the veins of the upper limb seems countless. There are reports of new discovered variants of the veins of the upper limb constantly. Continuous update increases the number of anatomical variants of the veins of the upper limb. Updating these patterns is especially important in vascular procedures $[6,7]$.

\section{CASE REPORT}

During preparation of one of the upper limbs for the educational purposes an unusual pattern of superficial and deep veins system was noticed.
As can be seen on the photography of the left upper limb was observed the unusual pattern of the basilic and cephalic vein (Fig. 1). Basically, the cephalic and basilic vein runs up along both side of forearm. Then, both veins enter the arm, avoiding the area of the cubital fossa but in our case they ran directly to the elbow pit where unexpected they both fused to form one of two main brachial veins. For this publication it was called superficial brachial vein. As can be seen on Figure 1 the second brachial vein has been formed fully separately by the veins of the deep system.

According to classical textbooks both brachial veins, near the armpit should join together to create singular axillary vein. As can be seen, each of brachial veins ran separately along the whole arm up to the axillary cavity. They both became axillary veins and ran, still separately, upwards. The axillary vein, which was formed by the superficial brachial vein, was named the accessory axillary vein.

One has an irresistible impression when looking at the photograph that the blood flowing from the upper limb rolls along two independent vessel systems. One system runs superficially, independently of the arteries, up to the axillary cavity, the other one is located deeper and accompanies the arteries of the 
upper limb. This pattern of blood circulation in the upper limbs seems to be unique and has not been published so far.

The work was approved by the Local Ethics Committee of Pomeranian Medical University in Szczecin.

\section{DISCUSSION}

The traditional anatomy texts offer a lot of description of the upper arm veins and are particularly abundant in regards to their variations $[6,8,12]$.

Bardeleben [2] was one of the first authors to provide a systematic nomenclature of the veins of the upper limbs and their topography. He also described about 36 varieties. However, in none of them was a description similar to the presented case [2]. Also the detailed classification of the superficial and deep upper limb veins is given by Vazquez et al. [14]; however, among these 11 variants there is also no description similar to the presented case.

Although the literature describes some types of anatomical variants of the veins of the upper limb, we have established that this pattern has not yet been published [1, 6, 8-10]. It has been found a report which describes an anatomical variant of the basilic and cephalic vein that is slightly similar to our case. But in their case the deep system was joined with the superficial system in the cubital fossa [11]. The occurrence of accessory axillary vein is estimated quite high, over $50 \%$. Charpy [3] was the first to describe this variability, but there were no similar descriptions to the presented case. Similarly, Gusmao and Prates [5] in their observations noted that the basic branches forming the accessory axillary vein originated from the deep vessel system, which sometimes received the branches from the superficial system. The authors did not encounter the accessory axillary vein formed exclusively by the veins from superficial system [5]. Unlike the basilic vein, which is characterized by some topographic instability, many reports indicate a fairly stable course of the cephalic vein [10, 12]. However, several variants of the cephalic vein have been already described. Del Sol et al. [4] and Ukoha et al. [13] in their research indicated six pattern varieties of the vein course in the area of the ulnar fossa; however, none of the given variants was similar to ours. It may be another proof that variability of the cephalic vein is not a rare phenomenon, as it is supposed to be $[1,10$, 12]. Some authors have emphasized the importance of identifying some variants of cephalic vein for surgical procedures, especially vascular or orthopaedic $[8,10]$.
They especially point out some procedures, such as creation of arteriovenous fistulas, where transposition of veins in some variants could increase the risk of complications $[1,8]$. Some authors suggest vein mapping before surgery to minimise the risk of some complications resulting from unexpected variants [1].

The presence of two large veins in the axillary cavity was demonstrated by ultrasound examination in patients undergoing vascular procedures. The authors regarded one of these veins as the accessory axillary vein. At this point, should be emphasized the importance of radiologic tools in anatomical exploration on the living. However, the authors concluded that anatomical dissection should be the basis for transferring the new anatomical pattern to other descriptions, e.g. radiological.

The above conclusion can be seen when editing radiological or surgical atlases. Therefore, cross-sectional studies should be still continued.

\section{CONCLUSIONS}

The catalogue of patterns of the upper limb venous system seems to be unlimited and should therefore be constantly updated. During each vascular surgery the probability of anatomical and topographic variability of the venous system of the upper limb should be taken into account.

\section{Acknowledgements}

Special thanks to Mr. J. Smolenski for help in the dissecting works.

\section{Conflict of interest: None declared}

\section{REFERENCES}

1. Anaya-Ayala JE, Younes HK, Kaiser CL, et al. Prevalence of variant brachial-basilic vein anatomy and implications for vascular access planning. J Vasc Surg. 2011; 53(3): 720-724, doi: 10.1016/j.jvs.2010.09.072, indexed in Pubmed: 21144691.

2. Bardeleben K. Die Hauptvene des Armes, vena capitalis brachii. Jenaische Zeitschrift 1880, 586-606 mit Tafeln XXVIII.

3. Charpy A. Systeme veineux. Veines du membre superieur. Traite d'anatomie humaine. Chapter IV. 1903: 904-924.

4. Del Sol M, Mardones LM, Bustos JE. Venous formations in the cubital fossa of Mapuche. Bioscopy study. Int J Morph. 2007; 23: 885-894.

5. Gusmao LC, Prates JC. Anatomical study of the accessory axillary vein. Surg Radiol Anat. 1992; 14(2): 131-136, doi: 10.1007/BF01794889, indexed in Pubmed: 1641737.

6. Kaiser $\mathrm{CL}$, Anaya-Ayala JE, Ismail N, et al. Unrecognized basilic vein variation leading to complication during basilic vein transposition arteriovenous fistula creation: case report and implications for access planning. Eur J Vasc 
Endovasc Surg. 2010; 39(5): 627-629, doi: 10.1016/j. ejvs.2010.01.011, indexed in Pubmed: 20172752.

7. Lee HS, Song YR, Kim JK, et al. Anatomical variants of upper arm veins on preoperative mapping venography for hemodialysis access in Korean adults. J Vasc Access. 2019; 20(3): 270-275, doi: 10.1177/1129729818803870, indexed in Pubmed: 30306819.

8. Loukas M, Myers CS, Wartmann ChT, et al. The clinical natomy of the cephalic vein in the deltopectoral triangle. Folia Morphol. 2008; 67(1): 72-77, indexed in Pubmed: 18335417.

9. Mikuni Y, Chiba S, Tonosaki Y. Topographical anatomy of superficial veins, cutaneous nerves, and arteries at venipuncture sites in the cubital fossa. Anat Sci Int. 2013; 88(1): 46-57, doi: 10.1007/s12565-012-0160-z, indexed in Pubmed: 23131916.

10. Radkowski CA, Richards RS, Pietrobon R, et al. An anatomic study of the cephalic vein in the deltopectoral shoulder approach. Clin Orthop Relat Res. 2006; 442: 139-142, doi: 10.1097/01.blo.0000181146.78434.da, indexed in Pubmed: 16394752.

11. Sadeghi A, Setayesh Mehr M, Esfandiari E, et al. Variation of the cephalic and basilic veins: A case report. J Cardiovasc Thorac Res. 2017; 9(4): 232-234, doi: 10.15171/ jcvtr.2017.40, indexed in Pubmed: 29391938.

12. Sandhu NPS, Sidhu DS. Mid-arm approach to basilic and cephalic vein cannulation using ultrasound guidance. $\mathrm{Br}$ J Anaesth. 2004; 93(2): 292-294, doi: 10.1093/bja/aeh179, indexed in Pubmed: 15194622.

13. Ukoha UU, Oranusi CK, Okafor Jl, et al. Patterns of superficial venous arrangement in the cubital fossa of adult Nigerians. Niger J Clin Pract. 2013; 16(1): 104-109, doi: 10.4103/11193077.106777, indexed in Pubmed: 23377482.

14. Vazquez T, Sanduo J. Veins of the upper limb. Bergman's Comprehensive Encyclopedia of Human Anat Variation. Ed: Tubbs RS, Shoja MM, Loukas MM. Willey Pub 2016: 826-830. 